\title{
RFRIST Study (Fractional Flow Reserve in Functional Quantification of Renal Allograft Artery Stenosis): Rationale and Study Design
}

\author{
Alexandre Vidal Bonfim ${ }^{1}$, Claudia Maria Rodrigues Alves², Adriano Henrique Pereira Barbosa ${ }^{3}$, \\ José Osmar Medina Pestana ${ }^{4}$, Marcelo Costa Batista ${ }^{5}$, Antônio Carlos Carvalho ${ }^{6}$
}

\begin{abstract}
Background: Renal allograft artery stenosis is the most prevalent vascular complication after renal transplantation. The diagnostic limitations of noninvasive tests are well defined and angiography remains the gold standard for diagnosis and therapeutic definition. The use of fractional flow reserve for a better stratification of native renal artery stenosis may be useful for an adequate selection of patients for percutaneous treatment, however this method has not yet been validated in patients undergoing transplantation. The objective of this study is to describe and standardize the fractional flow reserve protocol in patients with renal allograft artery stenosis in a group of patients selected for percutaneous renal intervention, correlating the method with angiography Methods: Cross-sectional, single center pilot study (Hospital São Paulo/ Universidade Federal de São Paulo, São Paulo, SP, Brazil), including 10 patients with a clinical picture compatible with renal allograft artery stenosis, with angiography showing graft stenosis $>60 \%$ and admitted for percutaneous renal intervention. Graft dysfunction assessment will include biomarkers of renal function. Conclusions: In this study, a fractional flow reserve protocol for the functional assessment of renal allograft artery stenosis will be standardized, evaluating an alternative method capable of identifying patients most likely to benefit from percutaneous renal intervention.
\end{abstract}

DESCRIPTORS: Renal artery obstruction. Kidney transplantation. Renal insufficiency, chronic.

\section{RESUMO}

Estudo RFRIST (Reserva de Fluxo Fracionada na
Quantificação Funcional das Estenoses em Artérias de
Rins Transplantados): Racional e Desenho do Estudo

Introdução: A estenose da artéria do enxerto renal é a complicação vascular mais prevalente após transplante renal. As limitações dos exames não-invasivos para seu diagnóstico são bem definidas e a angiografia permanece como padrão de referência para diagnóstico e definição terapêutica. A utilização da reserva de fluxo fracionada renal para melhor estratificação das estenoses de artéria renal nativa pode ajudar na adequada seleção de pacientes para tratamento percutâneo porém tal método ainda não está padronizado em pacientes submetidos a transplante. O objetivo deste estudo será descrever e padronizar o protocolo de reserva de fluxo fracionada em pacientes com estenose da artéria do enxerto renal em um grupo de pacientes selecionados para intervenção renal percutânea, correlacionando o método com a angiografia. Métodos: Estudo piloto, prospectivo, transversal, unicêntrico (Hospital São Paulo/Universidade Federal de São Paulo, São Paulo, SP, Brasil), em que serão selecionados 10 pacientes com quadro clínico compatível com estenose da artéria do enxerto renal, com angiografia do enxerto evidenciando estenose $\geq 60 \%$, admitidos para intervenção renal percutânea. Como avaliação da disfunção do enxerto serão realizadas dosagens de biomarcadores da função renal. Conclusões: No presente estudo, um protocolo original de reserva de fluxo fracionada para avaliação funcional de estenose da artéria do enxerto renal será padronizado, avaliando um método auxiliar na investigação funcional que possa identificar pacientes que realmente se beneficiem com a intervenção renal percutânea.

DESCRITORES: Obstrução da artéria renal. Transplante de rim. Insuficiência renal crônica.

\footnotetext{
${ }^{1}$ Postgraduate Physician at Hemodynamics and Interventionist Cardiology Sector of Escola Paulista de Medicina da Universidade Federal de São Paulo. São Paulo, SP, Brazil.

2 In-charged Physician for Hemodynamics and Cardiology Sector of Escola Paulista de Medicina da Universidade Federal de São Paulo. São Paulo, SP, Brazil.

3 Physician at Hemodynamics and Interventionist Cardiology Sector of Escola Paulista de Medicina da Universidade Federal de São Paulo. São Paulo, SP, Brazil.

${ }^{4}$ Principal Professor of Nefrology at Escola Paulista de Medicina da Universidade Federal de São Paulo. São Paulo, SP, Brazil.
}

\footnotetext{
${ }^{5}$ Principal Professor of Nefrology at Escola Paulista de Medicina da Universidade Federal de São Paulo. São Paulo, SP, Brazil.

${ }^{6}$ Principal Professor of Cardiology at Escola Paulista de Medicina da Universidade Federal de São Paulo. São Paulo, SP, Brazil.
}

Correspondence to: Alexandre Vidal Bonfim. Rua Botucatu, 740 - Vila Clementino - São Paulo, SP, Brazil - CEP 04023-900

E-mail: dr_alexbonfa@yahoo.com.br 
$\mathbf{R}$ enal transplantation has been performed for the treatment of patients with chronic renal failure since 1954. Nevertheless, renal transplantation can give rise to urologic, vascular, and even clinical complications due to the use of immunosuppressive drugs.

Vascular complications are infrequent in kidney transplantations; however, they are one of the major causes of morbidity and mortality, occasionally resulting in renal graft dysfunction, graft removal, or death., ${ }^{1,2}$ Among the vascular complications are renal graft artery stenosis, arteriovenous fistula, and renal vein thrombosis. Renal graft artery stenosis is the most common and occurs in $1 \%$ to $15 \%$ of transplanted patients. ${ }^{3-5}$ According to the United States Renal Data System registry, 41,867 renal transplantations were performed in the period from 2000 to 2005, of which 823 developed renal graft artery stenosis, corresponding to a rate of 8.3 cases per 1,000 patient-years. ${ }^{6}$ According to data from the Brazilian Transplantation Registry, 19,101 procedures were performed in that same period, but no data are available regarding the incidence of renal graft artery stenosis. ${ }^{7}$ In the present institution, Lopes et al. ${ }^{8}$ reported a renal graft artery stenosis rate of approximately $1.6 \%$.

Although no specific study has confirmed the association between vascular complications and graft position, the most often used technique is graft implantation in the common iliac or external artery, using termino-lateral anastomosis due to its speed and simplicity. The main causes of renal graft artery stenosis are inappropriate suture due to technical failure, intimal lesion during graft perfusion or when performing the implant, and excessive length of the renal artery causing torsion or tension at the suture site..$^{1,4-9}$ Atherosclerosis and fibrosis at the anastomosis site are also causes of renal artery stenosis, and generally occur at a later stage after transplantation. ${ }^{9}$

In general, clinical findings that suggest renal graft artery stenosis are severe arterial hypertension refractory to drug treatment, and audible murmur at the site of the graft associated with unexplained progressive graft dysfunction. The presence of hypertension in renal transplantation recipients is a clinical finding in 50\% to $60 \%$ of cases in the long-term. ${ }^{9,10}$ In the study by Mendes et al., ${ }^{9}$ in all cases of haemodynamically significant renal graft artery stenosis (defined as stenosis $>60 \%$ ), there was progressive loss of graft function and difficult-to-control hypertension (with the use of three or more antihypertensive drugs).

Colour Doppler ultrasonography is an excellent diagnostic method for initial assessment of renal graft artery stenosis, with a sensitivity of $94 \%$ and a specificity of $87 \%$ when compared to conventional angiography. ${ }^{10}$ Computed tomography angiography (CTA) has a sensitivity and a specificity of $100 \%$ and $96 \%$, respectively; its disadvantages are the use of ionising radiation and iodinated contrast. ${ }^{11}$ Magnetic resonance angiography (MRA) using gadolinium has been shown to be a good method for the detection of renal artery stenosis. Korst et al. ${ }^{12}$ found a sensitivity and a specificity of $100 \%$ and $85 \%$, respectively. It is an excellent technique for patients with impaired renal function and allergy to iodinated contrast medium, in whom digital angiography cannot be performed. ${ }^{13}$

In general, all patients submitted to renal transplantation at this institution who have high clinical suspicion of graft stenosis undergo Doppler ultrasound assessment, and when the results are altered (peak systolic velocity $>180 \mathrm{~cm} / \mathrm{s}$ ), a renal angiography is indicated. Angiography, an examination considered to be the gold standard for the definitive diagnosis of renal artery stenosis, is used to confirm the injury indicated by Doppler ultrasonography and/or CTA, and guides the therapeutic approach. However, angiography is based on findings of visual estimation or by quantitative renal angiography (QRA), thereby determining the severity of a stenosis while quantifying t. Stenoses are considered severe when there is $>60 \%$ of vessel lumen obstruction. ${ }^{7,11}$

Once the diagnosis is attained, treatment options include percutaneous treatment using a conventional percutaneous intervention with a balloon or, preferably, stenting (percutaneous renal intervention [PRI]) and revascularisation surgery. The PRI results in resolution or improvement in $76 \%$ of cases, with the discontinuation of at least two antihypertensive medications, and in some patients already on dialysis, it is possible to achieve graft function recovery. ${ }^{7}$ Success rates are high, and restenosis with stenting is below $10 \%$, mainly due to the high luminal diameter of the vessel and the immunosuppressive therapy used after transplantation. ${ }^{7,9}$

In contrast, some patients submitted to renal graft angiography have moderate stenosis ( $>30 \%$ and $<60 \%$ ), in addition to cases in which the visual estimation/ QRA cannot define the actual severity of the stenosis. This usually occurs in stenosis with ostial location or even as a result of the limitations of luminography. In this scenario, the idea of using a method that would help in the functional stratification of renal graft artery stenosis has been proposed. Developed and validated for the functional stratification of coronary stenosis, the fractional flow reserve for native renal artery stenosis has been studied by Leesar et al. ${ }^{14}$ and Kapoor et al. ${ }^{15}$ These studies evaluated the severity of stenosis based on the maximum and mean translesional systolic pressure gradients, and based on the association between maximum systolic pressure in the aorta and pressure distal to the stenosis $(\mathrm{Pd} / \mathrm{Pa})$, measured by the pressure wire during maximum hyperaemia induced by $30 \mathrm{mg}$ papaverine infused as an intrarenal bolus. To predict the severity of native renal artery stenosis, accuracy, sensitivity and specificity of $84 \%, 82 \%$, and $84 \%$ were 
determined, respectively, for maximum systolic gradient $>21 \mathrm{mmHg}$, and $79 \%, 82 \%$, and $88 \%$, respectively, for a $\mathrm{Pd} / \mathrm{Pa}$ ratio $<0.9$.

Regarding renal graft artery stenosis, there have been no studies that used fractional flow reserve for the functional analysis of these stenoses. Thus, the usefulness of this method in the functional evaluation of these patients and the possibility of predicting the therapeutic effectiveness of the PRI has not yet been explored.

\section{METHODS}

\section{Fractional flow reserve: definitions and principles}

Renal fractional flow reserve is defined as the ratio between the maximum blood flow to the renal parenchyma in the presence of a determined stenosis (or stenoses) and this same flow if there were no stenoses. This ratio represents the fraction of normal maximum renal flow that can be achieved in the presence of stenosis. The fractional flow reserve can be readily determined by dividing the mean pressure distal to the renal lesion by the mean pressure in the aorta during maximal vasodilation induced by administering an intra-arterial bolus dose of $30 \mathrm{mg}$ papaverine in the renal graft. A fractional flow reserve of 0.6 indicates that the maximum amount of blood (and oxygen) that irrigates that particular area of renal tissue is only $60 \%$ of what it would be if the culprit artery was completely normal. If, after a PRI, the fractional flow reserve in that case increases to 0.90 , it means the maximum achievable flow into the parenchymal area supplied by that artery (and hence, the oxygen supply) increased by $50 \%$ and is now $90 \%$ of the attainable value if the artery was completely normal. Figures 1 and 2 show, schematically, how to determine the fractional flow reserve and how the flow measurement can be inferred by dividing pressures.

\section{Protocol description}

\section{Study goals}

1. To describe and standardise the study protocol of fractional flow reserve in patients with severe stenosis of the renal graft artery who are selected for PRI, observing whether the cutoff used for native renal artery stenosis (maximum systolic gradient $>$ $21 \mathrm{~mm}$ or $\mathrm{Pd} / \mathrm{Pa}<0.9$ ) is reproducible for renal graft artery stenosis.

2. To compare the results obtained through direct measurements of pressure gradients (pre- and poststenosis) at rest and after hyperaemic stimulation performed with a conventional $4 \mathrm{~F}$ catheter, as well as the pressure measured by the pressure wire.

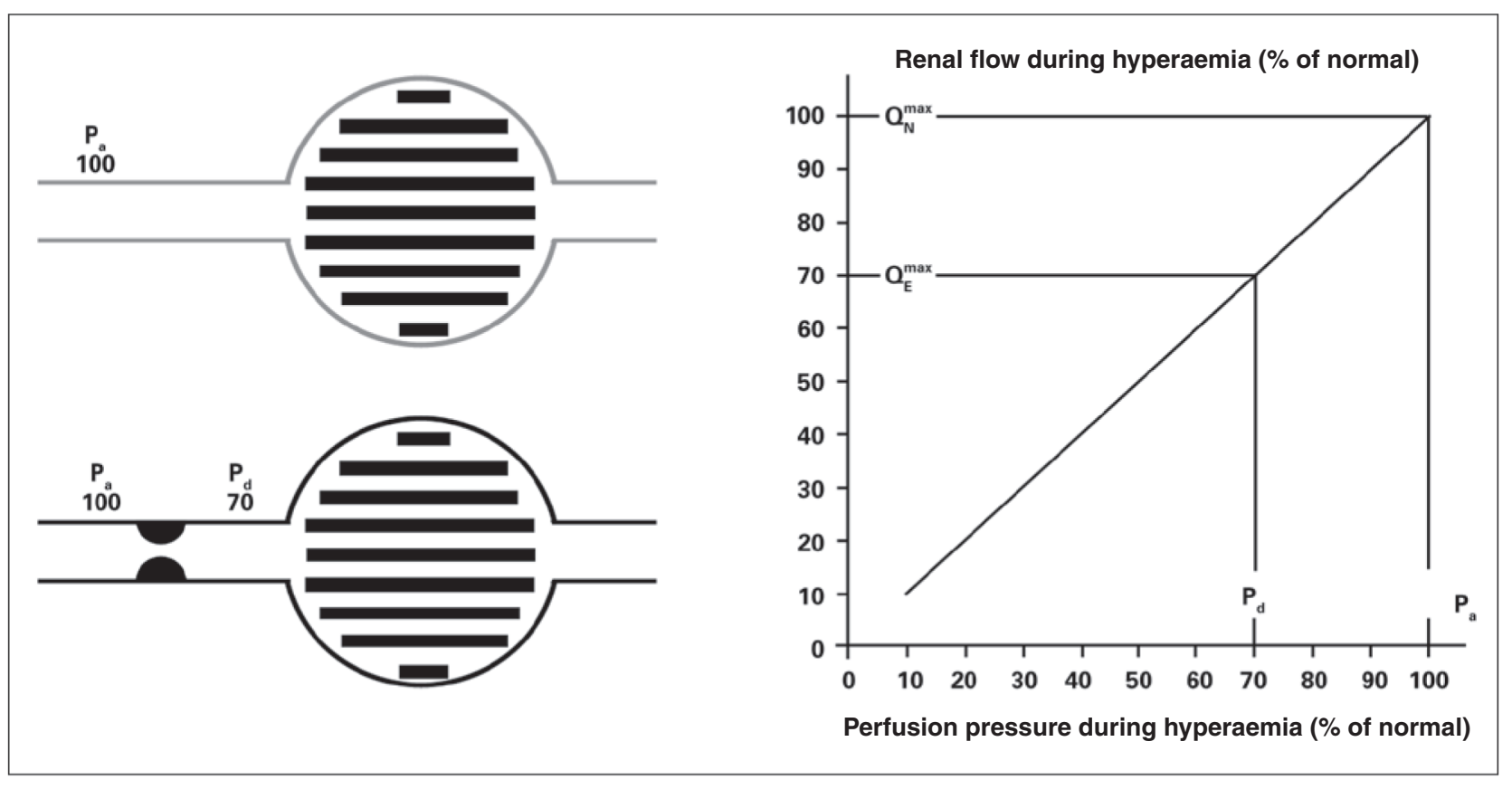

Figure 1 - Definition of renal fractional flow reserve. If there is no stenosis (gray lines), the perfusion pressure determines the maximum normal flow rate $(100 \%)$ of the renal parenchyma $\left(\mathrm{P}_{\mathrm{a}}=\mathrm{P}_{\mathrm{d}}\right)$. In case of stenosis (black lines), responsible for a gradient of $30 \mathrm{mmHg}$ during maximum hyperaemia, the distal perfusion pressure will decrease to $70 \mathrm{mmHg}$. As the ratio between renal flow and pressure is linear during hyperaemia (chart), renal flow will reach only $70 \%$ of its normal value. $P_{a^{\prime}}$ perfusion pressure, $P_{d^{\prime}}$ distal pressure. 
Pressure $(\Delta \mathrm{P})=$ Flow $(\mathbf{Q}) \times$ Resistance $(\mathbf{R})$ $\mathbf{Q}=\Delta \mathbf{P} / \mathbf{R}$

$$
\begin{aligned}
& F F R_{\text {mio }}=\frac{\mathbf{Q}^{\text {Stenosis }}}{\mathbf{Q}^{\text {Normal }}}=\frac{\left(\mathbf{P}_{\mathrm{d}}-\mathbf{P}_{/} / \mathbf{R}_{\text {phio }}^{0}\right.}{\left(\mathbf{P}_{\mathrm{A}}-\mathbf{P}_{/ \Delta} / \mathbf{R}_{\text {grio }}\right.}=\frac{\mathbf{P}_{\mathrm{d}}}{\mathbf{P}_{\mathrm{A}}} \\
& \text { Hydraulic equation }
\end{aligned}
$$

Figure 2 - Renal fractional flow reserve is calculated by dividing the distal pressure in the renal artery by the pressure in the aorta during maximum hyperaemia. FFR, fractional flow reserve, $\mathrm{Q}^{\text {Stenosis, }}$, flow in renal graft artery with stenosis; $\mathrm{Q}^{\text {Normal }}$, flow in the renal graft artery in the absence of stenosis; $P_{d^{\prime}}$ distal pressure; $P_{V^{\prime}}$ venous pressure; $P_{A^{\prime}}$ pressure in the aorta; $\mathrm{R}_{\mathrm{MIO}}$, renal resistance.

3. To evaluate the association between fractional flow reserve values before and after the procedure and procedural success through ultra-sensitive markers of renal function.

\section{Study population}

A total of ten 15 to 65 year-old patients will be initially assessed, after an informed consent is signed. The patients will have been referred to the Interventional Cardiology Service of the Hospital São Paulo (Escola Paulista de Medicina, Universidade Federal de São Paulo (UNIFESP/EPM), São Paulo, SP, Brazil), with a clinical picture of renal graft artery stenosis, associated with Doppler ultrasound and/or CTA suggestive of renal graft artery stenosis to undergo renal angiography and, when the presence of this stenosis is confirmed, will have an indication for PRI (renal graft artery stenosis $\geq 60 \%$ at visual estimation). The project was approved by the research ethics committee, protocol No. 51,518 - Plataforma Brasil - Brazilian Ministry of Health. Figure 3 summarises the study design. Patients will be admitted 12 hours before the procedure, and intravenous hydration will be carried out with $0.9 \%$ saline solution at $1 \mathrm{~mL} / \mathrm{kg} /$ hour, 12 hours before and after the test. Low-osmolarity contrast will be used to minimise the risk of contrast-induced nephropathy. Dual antiplatelet therapy will be administered (with $300 \mathrm{mg}$ acetylsalicylic acid and $300 \mathrm{mg}$ clopidogrel, 12 hours prior to the procedure). A dose of $100 \mathrm{mg}$ acetylsalicylic acid will be maintained indefinitely, as well as $75 \mathrm{mg}$ clopidogrel for 30 days.

The angiograms of all patients selected for the study will be analysed by an experienced interventional physician. Then, artery lesions considered to be severe (visual estimates showing stenosis $\geq 60 \%$ ), and thus with an indication for PRI, will be submitted to the protocol for the analysis of the mean systolic translesional pressure gradients and fractional flow reserve pre- and post-treatment under hyperaemia with papaverine.

\section{Materials}

$6 \mathrm{~F}$ or $7 \mathrm{~F}$ therapeutic guide-catheters without lateral holes will be used for selective catheterisation of the artery to be approached. The measurement of the translesional pressure gradient will be mandatorily performed with $4 \mathrm{~F}$ guide catheters, as larger-calibre catheters interfere with the assessment of stenosis during their retreat to perform the gradient measurement. The guidewire to be used for measurement of fractional flow reserve uses a specific sensor located $3 \mathrm{~cm}$ from its tip, has a diameter of 0.014 inch $(0.36 \mathrm{~mm})$, and has a soft tip, similar in calibre to the guide wires routinely used in PRI procedures. PressureWire Certus Hydrophilic ${ }^{\circledR}$ guidewires (Radi Medical Systems AB Inc., Uppsala, Sweden) will also be used. The guide wire is connected to a monitor, which, by converting the pressure signal to an electrical signal, presents the results directly on the screen, allowing the data to be viewed and saved in a few seconds.

The angiograms will be performed with Philips Allure FD10 equipment (flat panel), which has software with appropriate settings for acquisition and processing of images in rotational angiography of the abdomen.

\section{Hyperaemia}

It is essential to induce maximal vasodilation in the two compartments of renal circulation, in the vessel itself and in the microcirculation, to calculate the renal fractional flow reserve. Administration of $30 \mathrm{mg}$ papaverine by an intra-arterial route in bolus is the available option. The drug's action lasts up to 50 seconds; it has no side effects and can be used in catheter withdrawal manoeuvres. The systolic and mean translesional gradients are calculated simultaneously during the analysis of the renal fractional flow reserve.

\section{Systematisation for the initial angiographies, angiographic definition of lesion severity, measurement of renal fractional flow reserve, and PRI with a stent and new measurement of fractional flow reserve.}

A total of ten patients who have a clinical picture of renal artery graft stenosis and angiography showing graft stenosis $\geq 60 \%$ and are admitted to undergo PRI will be selected. For the evaluation of graft dysfunction, serum measurements of urea and creatinine will be performed 12 hours before and 12 and 72 hours after the procedure. Measurement of urinary neutrophil gelatinase-associated lipocalin (NGAL), interleukin-18 (IL-18), kidney injury molecule-1 (KIM-1), and serum cystatin $\mathrm{C}$ will be performed at the beginning and 6 hours, 12 hours, 24 hours, and 48 hours after the procedure. 


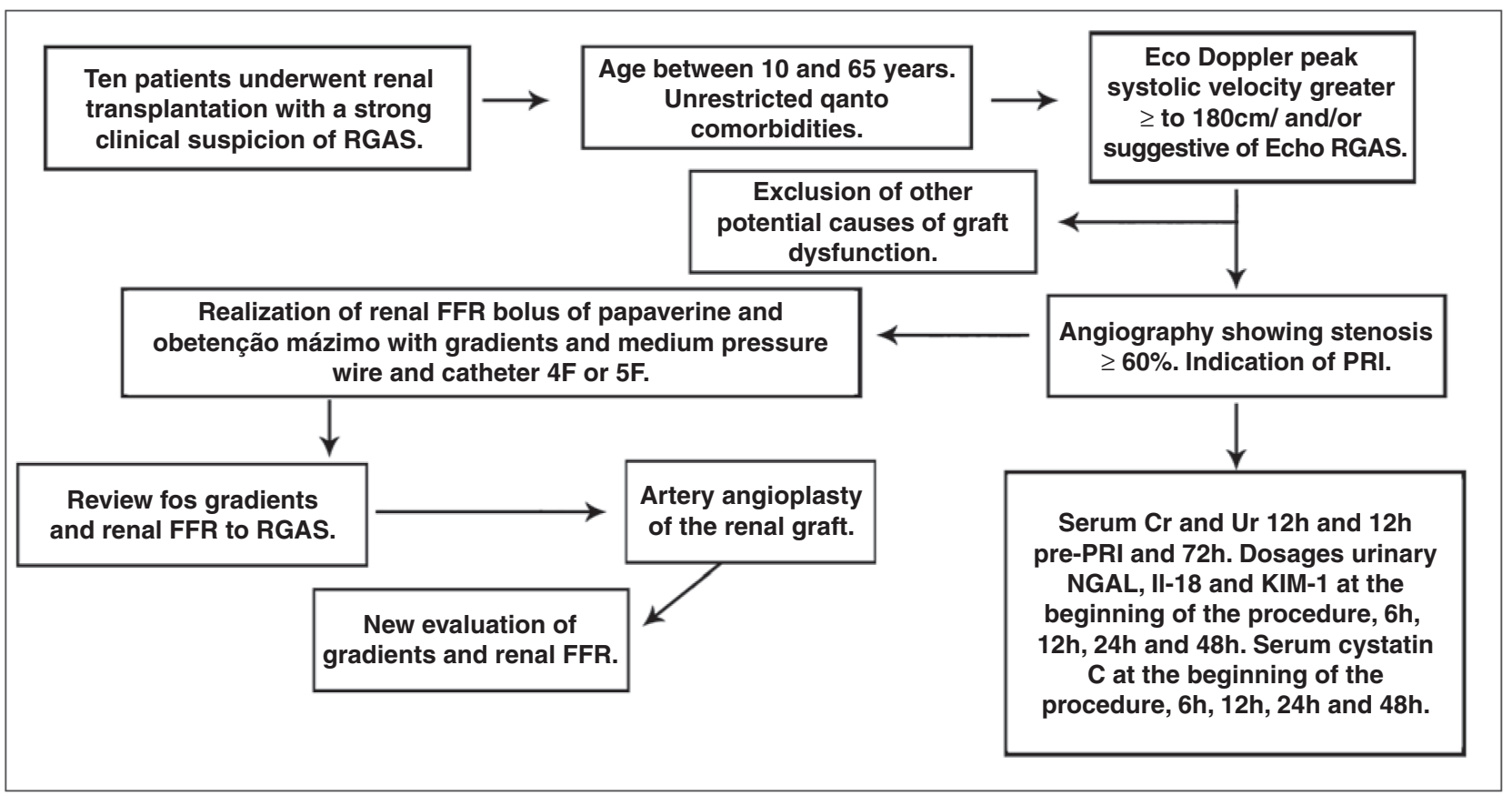

Figure 3 - Overview of the study protocol. RGAS, renal graft artery stenosis; Echo, echocardiography; CTA, computed tomography angiography; FFR, fractional flow reserve; PRI, percutaneous renal intervention; Ur, urea; Cr, creatinine; NGAL, neutrophil gelatinase-associated lipocalin; IL-18, interleukin-18; KIM-1, kidney injury molecule-1.

The following steps will be performed during the procedure:

1. Local anaesthesia of the arterial puncture site with $2 \%$ lidocaine $(10-15 \mathrm{~mL})$.

2. Insertion of a $6 \mathrm{~F}$ or $7 \mathrm{~F}$ arterial sheath.

3. Introduction of a $4 \mathrm{~F}$ Judkins right (JR) catheter after the stenosis and maximum hyperaemia induced with $30 \mathrm{mg}$ papaverine in bolus followed by evaluation of translesional gradients.

4. Selective catheterisation of the renal graft artery with an RDC guide catheter or a JR 4 of PRI, 6F, or 7F without lateral holes.

5. Administration of $100 \mathrm{UI} / \mathrm{kg}$ IV heparin.

6. Calibration of guide-catheter and pressure wire.

7. Connection of the pressure wire to the analyser, equating the pressures of the guide-catheter and wire pressure when the sensor of the latter is close to the tip of the guide-catheter.

8. Placement of the pressure wire in the distal bed of the renal graft artery to be analysed.

9. Evaluation of graft stenosis by measuring the fractional flow reserve during maximum hyperaemia induced by an intra-arterial injection of $30 \mathrm{mg}$ papaverine in bolus in the renal graft.
10. Performing PRI with stent implantation.

11. New gradient assessment through maximum hyperaemia with papaverine using the pressure wire and a $4 \mathrm{~F}$ catheter.

\section{Procedural success analysis}

Angiographic success

Procedural angiographic success will be considered when the stenosis is resolved after the PRI (residual $\leq 30 \%)^{7}$ with no major complications.

\section{Functional success}

Following the principles established by the hydraulic equation to calculate the renal fractional flow reserve as shown in Figure 2, after normalising the flow with the resolution of the previously existing stenosis, there should be no pressure difference between the pressure distal to the treated site and the proximal pressure $(\mathrm{Pd}$ $=\mathrm{Pa})$, which means that the $\mathrm{Pd} / \mathrm{Pa}$ ratio $=1$. Likewise, the resolution of the systolic and mean translesional pressure gradients can be estimated.

To analyse renal function improvement, kidney injury markers, which have been developed and validated to predict the degree of renal dysfunction, will be quantified. The most commonly used laboratory parameter for the clinical diagnosis of acute renal failure (ARF) 
is the elevation in plasma creatinine. However, it is necessary that the glomerular filtration rate is reduced by $50 \%$ in order to increase the creatinine. The ideal biomarker should be quick and easy to measure, obtainable through minimally invasive procedures, and capable of detecting early tubular injury and reflecting changes of renal function. Currently, KIM-1, IL-18, $\mathrm{NGAL}$, and cystatin $\mathrm{C}$ are considered as the urinary molecules with the greatest potential for early detection of acute kidney injury for clinical use. ${ }^{16,17}$

Parikh et al. ${ }^{18}$ evaluated the urinary measurement of NGAL associated with lipocalin in 63 patients submitted to renal transplantation and found a sensitivity and specificity of $90 \%$ and $83 \%$, respectively, to predict ARF (cutoff of $53 \mathrm{pg} / \mathrm{mL}$ ) measured two hours after transplantation. The same authors also evaluated the measurement of IL-18 with excellent results in predicting ARF in post-renal transplantation.

Therefore, the measurements of the renal injury markers (IL-18, NGAL, urinary KIM-1, and serum cystatin C) will be performed shortly before the procedure (time zero), 6, 12, 24, and 48 hours after the PRI, and their values will be compared with the plasma creatinine measured 12 hours before and 12 and 72 hours after PRI. Consequently, it will be possible to assess the effects of the procedure (handling of arterial stenosis, contrast-induced nephropathy) associated with improved perfusion of the renal parenchyma after stenosis resolution.

\section{Statistical analysis}

Due to the small number of patients in this pilot study, it is possible that much of the data will not be comparable. This project will serve to establish the submission method for a supplemental project to the funding agency and sample expansion. The most important data collected here will be the difference between fractional flow reserve before and after treatment, assuming that the same value found in studies of native artery stenosis is reproduced here (fractional flow reserve of 0.9 ).

Continuous variables will be expressed as the means and standard deviations and compared by Student's t-test. Categorical variables will be described as absolute frequencies and compared by the chi-squared test. Spearman's test will be used for the correlation between the haemodynamic parameters of the study and the percentage of renal graft artery stenosis at visual estimation. The Wilcoxon test will be used to compare the measurements of kidney injury biomarkers before and after stent implantation at the times described. Pvalues $<0.05$ will be considered indicative of statistical significance. All analyses will be performed using the SPSS 11.5 software package (SPSS - Chicago, USA). It is noteworthy that, due to the small sample size, there will not be sufficient statistical power to evaluate the efficiency of PRI in the context of treatment for renal graft artery stenosis.

\section{CONCLUSIONS}

The use of the fractional flow reserve for better stratification of renal graft artery stenosis may improve the selection of patients for percutaneous treatment, thus reducing risks and preserving resources. Since the study will be conducted with patients with confirmed diagnosis of severe renal graft artery stenosis (> 60\%), and since the patients will be treated regardless of the values found for fractional flow reserve, it will not be possible to conclude that the fractional flow reserve is an additive method for better stratification of stenoses, but only that the protocol was described in this sample. However, the results may be of great value for the development of future studies, expanding the use of methods and refining information obtained by other diagnostic tests.

Thus, a future study designed is being that can validate the fractional flow reserve as a method to stratify patients who can greatly benefit from PRI in the clinical scenario described, using a more robust sample of patients.

\section{CONFLICT OF INTEREST}

The authors declare no conflicts of interest

\section{REFERENCES}

1. Del Valle Sanz $Y$, Lorente Ramos RM, Berrocal Frutos $T$, Pietro Arellano C, Rodríguez Lemos R, García-Messeguer MC. Complicaciones vasculares en el transplante renal pediátrico: diagnóstico ecográfico. An Esp Pediatr. 1999;50(3):263-8.

2. Droupy $S$, Eschwège $P$, Blanchet $P$, Hammoudi $Y$, Bensadoun $H$, Bellamy J, et al. Recipient arterial repairs during renal transplantation. Transplant Proc. 2002;34(3):814.

3. Höhnke C, Abendroth D, Schleibner S, Land W. Vascular complications in 1,200 kidney transplantations. Transplant Proc. 1987;19(5):3691-2.

4. Sutherland RS, Spees EK, Jones JW, Fink DW. Renal artery stenosis after renal transplantation: the impact of the hypogastric artery anastomosis. J Urol. 1993;149(5):980-5.

5. De Bruney B, Monoharan G, Pijls NH, Verhamme K, Madaric J, Bartunek J, et al. Assessment of renal artery stenosis severity by pressure gradient measurements. J Am Coll Cardiol. 2006; 48(9):1851-5

6. Hurst FP, Abbot KC, Neff RT, Elster EA, Falta EM, Lentine KL, et al. Incidence, predictors and outcomes of transplant renal artery stenosis after kidney transplantation: analysis of USRDS. Am J Nephrol. 2009;30(5):459-67.

7. Associação Brasileira de Transplante de Órgãos (ABTO). RBT Registro Brasileiro de Transplante. 2010cited 15 Feb 2011;16(4). [cited 15 Feb. 2011]. Available from: http://www.abto.org.br/ abtov02/portugues/populacao/rbt/anoXVI_n4_completo/index. aspx

8. Lopes JAM, Almeida CJ, Hachul M, Srougi M. Frequência de estenose de artéria renal em 676 transplantes renais. Rev Assoc Med Bras. 1998;44(3):210-3. 
9. Mendes WDS, Silva LF, Espinosa G, Fernandes AL, Furtado R, Gonçalves R. Estenose arterial nos transplantes renais. Rev Bras Col Cir. 2005;32(5):237-43

10. De Cobelli F, Venturini M, Vanzulli A, Sironi S, Salvioni M, Angeli E, et al. Renal arterial stenosis: prospective comparison of color Doppler US and breath-hold, three-dimensional, dynamic, gadolinium-enhanced MR angiography. Radiology. 2000;214(2):373-80.

11. Hofmann LV, Smith PA, Kuszyk BS, Kraus E, Fishman EK. Three-dimensional helical CT angiography in renal transplant recipients: a new problem-solving tool. AJR Am J Roentgenol. 1999;173(4):1085-9.

12. Korst MB, Joosten FB, Postma CT, Jager GJ, Krabbe JK, Barentsz JO. Accuracy of normal-dose contrast-enhanced MR angiography in assessing renal artery stenosis and accessory renal arteries. AJR Am J Roentgenol. 2000;174(3):629-34.

13. Dong Q, Schoenberg SO, Carlos RC, Neimatallah M, Cho KJ, Williams DM, et al. Diagnosis of renal vascular disease with MR angiography. Radiographics. 1999;19(6):1535-54.
14. Leesar MA, Varma I, Shapira A, Fahsah I, Raza ST, Elghoul Z et al. Prediction of hypertension improvement after stenting of renal artery stenosis: comparative accuracy of translesional pressure gradients, intravascular ultrasound, and angiography. J Am Coll Cardiol. 2009;53(25):2363-71.

15. Kapoor N, Fahsah I, Karim R, Jevans AJ, Leesar AM. Physiological assessment of renal artery stenosis: comparisons of resting with hyperemic renal pressure measurements. Catheter Cardiovasc Interv. 2010;76(5):726-32

16. Mehta RL, Chertow GM. Acute renal failure definitions and classification: time for change?. J Am Soc Nephrol. 2003;14(8):2178-87.

17. Star RA. Treatment of acute renal failure. Kidney Int. 1998;54(6): 1817-31.

18. Parikh CR, Jani A, Mishra J, Ma Q, Kelly C, Barasch J, et al Urine NGAL and IL-18 are predictive biomarkers for delayed graft function following kidney transplantation. Am J Transplant. 2006;6(7):1639-45 